\title{
ST. JUDE MEDICAL: PULMONARY EDEMA MONITORING IN PACEMAKERS AND ICDS
}

\author{
A Thesis \\ presented to \\ the Faculty of California Polytechnic State University, \\ San Luis Obispo
}

In Partial Fulfillment

Of the Requirements for the Degree

Master of Biomedical Engineering

by

David Wei-Péng Chang

December 2013 
(C) 2013

David Wei-Péng Chang

ALL RIGHTS RESERVED 
COMMITTEE MEMBERSHIP

Title:

Author:

Date Submitted:

Committee Chair:

Committee Member:

Committee Member:
St. Jude Medical: Pulmonary Edema Monitoring in Pacemakers and ICDs

David Wei-Péng Chang

December 2013

Lily Hsu Laiho, Ph.D

Professor of Biomedical Engineering Kristen O'Halloran Cardinal, Ph.D

Professor of Biomedical Engineering Robert Crockett, Ph.D

Professor Biomedical Engineering 


\begin{abstract}
St. Jude Medical: Pulmonary Edema Monitoring in Pacemakers and ICDs David Wei-Péng Chang
\end{abstract}

Pulmonary edema occurs when fluid leaks from the pulmonary capillary network into the lung interstitium and alveoli. When the heart is not able to pump blood to the body efficiently, fluid can back up into the veins that take blood through the lungs to the left atrium. This then builds up the pressure in the blood vessels and fluid is pushed into the alveoli in the lungs. The fluid reduces normal oxygen movement through the lungs and can cause impaired gas exchange and respiratory failure. There are many causes of congestive heart failure that may lead to pulmonary edema such as heart attack, any diseases of the heart that weaken or stiffen the heart muscle, a leaking or narrowed heart valve, and sudden, severe high blood pressure.

Pulmonary edema is a strong indicator of congestive heart failure in patients and therefore can be used as a gauge for congestive heart failure. One way to diagnose cardiogenic pulmonary edema constantly is through the continuous monitoring of the transthoracic impedance throughout the day. One method to achieve this constant monitoring is through the use of a cardiac pacemaker or an implantable cardioverter 
defibrillator (ICD). Many patients who are at risk of heart failure have these medical devices implanted already. In these implantable cardiac devices, the connected cardiac leads can be utilized to continually screen several impedance vectors for decreases in impedance in the thoracic cavity. A pacemaker or ICD that implements Pulmonary Edema Monitoring is designed to continuously monitor these impedance vectors and alert the patient to seek medical attention. This thesis will discuss the implementation of Pulmonary Edema Monitoring via screening of multiple impedance vectors in a pacemaker or implantable cardioverter defibrillator and the effectiveness of this monitoring method. Furthermore, the design, implementation, and testing of this feature will be explored in greater detail.

Keywords: St Jude Medical, Implantable Cardioverter Defibrillators, Pacemakers, Medical Devices, Pulmonary Edema, Pulmonary Oedema, Congestive Heart Failure, Intrathoracic Impedance Monitoring. 


\section{TABLE OF CONTENTS}

\begin{tabular}{|c|c|}
\hline I. & 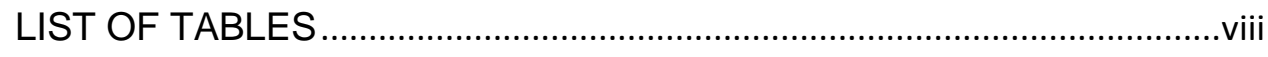 \\
\hline II. & LIST OF FIGURES .. \\
\hline \multicolumn{2}{|c|}{ Chapter } \\
\hline \multirow{4}{*}{ III. } & Background and Clinical Significance .............................. \\
\hline & Heart failure............................... \\
\hline & Pulmonary Edema (or Pulmonary Oedema) ........................... 3 \\
\hline & 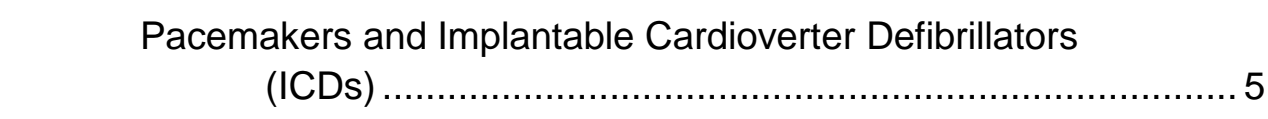 \\
\hline \multirow{4}{*}{ IV. } & Objectives \\
\hline & Project Objective ............................................................. 12 \\
\hline & Project Requirements .................................... \\
\hline & Project Theory ......................................... \\
\hline \multirow[t]{8}{*}{ V. } & 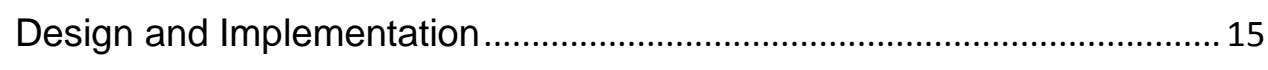 \\
\hline & Overview of Impedance Based Monitoring ................................. 15 \\
\hline & Fluid Index................................. \\
\hline & Impedance vectors .................. \\
\hline & Moving Average Integral.... \\
\hline & Negative Trend..................... \\
\hline & 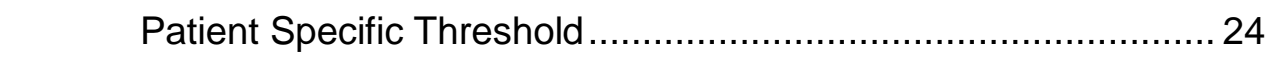 \\
\hline & 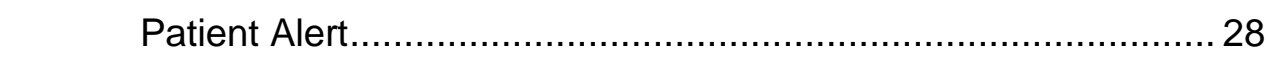 \\
\hline \multirow[t]{3}{*}{ VI. } & 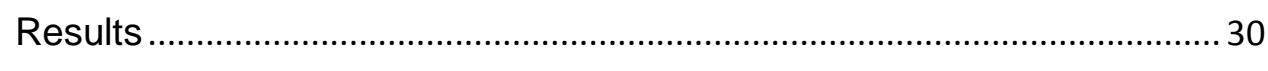 \\
\hline & Algorithm Optimization ................................................ \\
\hline & 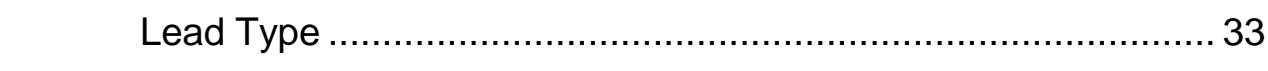 \\
\hline \multirow[t]{3}{*}{ VII. } & Discussion ................. \\
\hline & Strengths..... \\
\hline & Weaknesses. \\
\hline
\end{tabular}




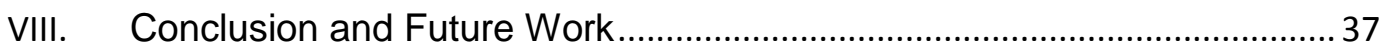

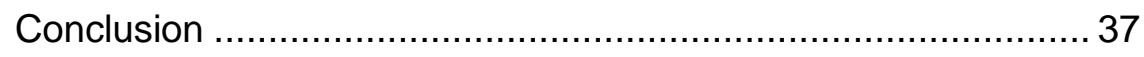

Future Work ................................................................... 38

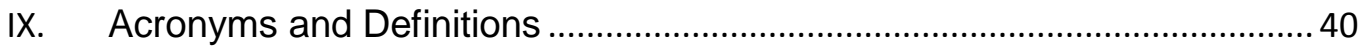

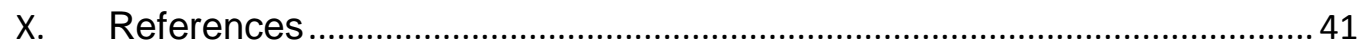




\section{LIST OF TABLES}

Table

Page

1. Parameter description used by all algorithms and what values were investigated.

2. This is a table of coefficients for weighting and adding vectors together. [14]

3. This table shows the displayed and actual programmable thresholds in coarse steps for a CRT-D device. 27

4. This table shows the displayed and actual programmable thresholds in coarse steps for an ICD device. 28

5. This table shows the optimal settings for the two algorithms [14].

6. This table shows the optimal settings and performance for each of the six single vectors for the Negative Trend algorithm. [14] 32

7. This table shows the optimal settings and performance for different device types for the Negative Trend algorithm. [14]. 33

8. This table shows the lead types with the impedance range used for US and outside of the US patients. [14] 


\section{LIST OF FIGURES}

$\begin{array}{lll}\text { Figure Page } & \end{array}$

1. Respondent-reported lifetime heart disease prevalence among

adults 18 years and over, by sex and age: United States, 1999-

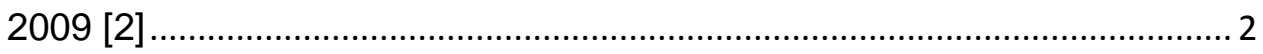

2. Fluid may build up in the alveoli or leak into the tissues around the

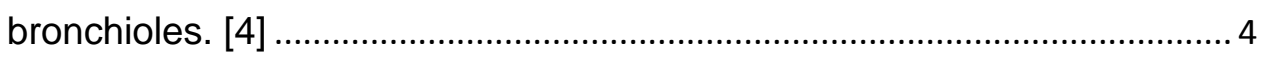

3. Pulmonary and Cardiac Edema progression. [5] ………….........................

4. Placement of ICDs and pacemakers in the upper chest of patients

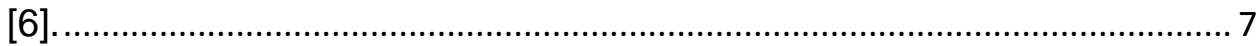

5. A high level depiction of a pacemaker or ICD taking an impedance

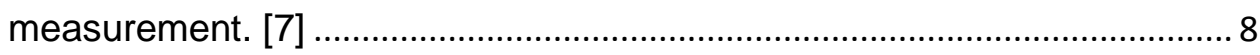

6. These graphs depict thoracic impedance measurements in a heart

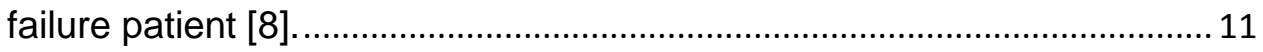

7. This shows a high level diagram for the fluid index algorithm. [14] ........... 18

8. This is the flow chart that describes the method used to calculate the Fluid Index. [Removed by SJM Legal] ………………………………..... 19

9. An example of Fluid Index (Negative Trend) for HF detection [14] ..........23

10. Patient specific threshold histogram that gives optimal performance for cardiac resynchronization therapy defibrillator (or CRT-D). 
11. Patient specific threshold histogram that gives optimal

performance for an ICD........................................................................ 26 


\section{Background and Clinical Significance}

\section{Heart failure}

Heart failure (HF) is widely known as the leading cause of death for both men and women in the United States. Approximately 600,000 people die of heart disease in the United States every year making the early detection and indication of heart failure a critical need [1]. Heart disease can be caused by many conditions such as coronary artery disease, heart attack, high blood pressure (hypertension), faulty heart valves, damage to the heart muscle (cardiomyopathy), myocarditis, heart defects (congenital heart defects), and abnormal heart rhythms. Figure 1 displays the significant increase in heart disease in men and women as they grow older. The percentage of men who report heart disease grows from just under $5 \%$ in the $18-44$ year age range to approximately $45 \%$ in the 75 year and older age range. The percentage of women who report heart disease grows from just under $5 \%$ in the $18-44$ year age range to approximately $30 \%$ in the 75 year and older age range. 

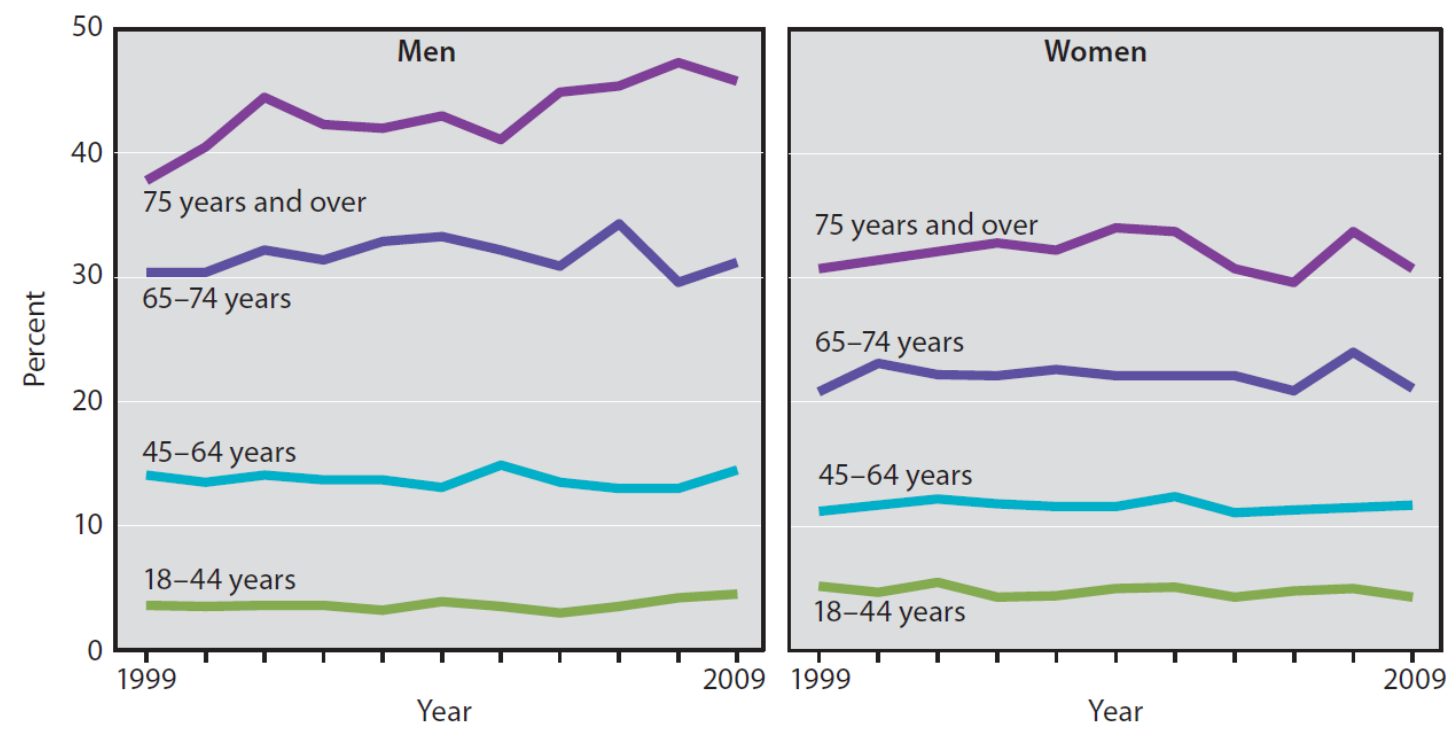

Figure 1: Respondent-reported lifetime heart disease prevalence among adults 18 years and over, by sex and age: United States, 1999-2009 [2]

In addition, major heart failure events result in hospitalization with clinical manifestations of cardiogenic pulmonary edema including lab work, imaging chest x-rays (used to analyze pleural effusion and increased vascular congestion), echocardiograms, and invasive hemodynamic monitoring. Major heart failure events can be confirmed by imaging and invasive monitoring and therapy. These are all costly procedures to perform and are sometimes invasive to the patient. The costs associated with heart failure amounted to an astonishing $\$ 29$ billion in medical costs in 2004 [3]. A decreased frequency of hospitalization improves patients' quality of life and may improve patient survival.

For these reasons, heart failure is widely studied and monitored closely in patients at risk of heart failure. Utilizing pulmonary edema as an indicator that 
heart failure is a potential threat in the immediate future is a useful way of alerting patients to life threatening conditions before they occur.

\section{Pulmonary Edema (or Pulmonary Oedema)}

Pulmonary edema (PE) has several causes, such as lung infections, exposure to toxins, kidney disease, adverse drug reactions, smoke inhalation, acute respiratory distress syndrome (ARDS), or high altitude exposure. Congestive heart failure (CHF) is an imbalance in pump function in which the heart fails to maintain appropriate blood circulation. The severest form of $\mathrm{CHF}$ is cardiogenic pulmonary edema (PE).

A normal heart is composed of two upper chambers, called atria, and two lower chambers, called ventricles. The atria receive incoming blood and pump the blood into the ventricles. The ventricles are the more muscular chambers that pump the blood out of the heart. Here in the heart, deoxygenated blood from the entire body flows into the right atrium and then is passed into the right ventricle. The right ventricle then pumps the blood through the pulmonary arteries to the lungs. In the lungs, the blood will release carbon dioxide and pick up oxygen. The oxygen-rich blood returns to left atrium of the heart through the pulmonary veins and then is passed to the left ventricle. From here, the blood is pumped out of the left ventricle through the aorta into the entire body.

In a heart where pulmonary edema develops, the imbalance in pump function causes an increase in lung fluid secondary to leakage from pulmonary capillaries into the interstitium and alveoli of the lungs. This fluid buildup in the 
alveoli makes it difficult to breathe, leads to impaired oxygen and carbon dioxide gas exchange, and may cause respiratory failure. As seen in Figure 2, clear alveoli allow for the constant flow of oxygen and carbon dioxide through the lungs. In the case of pulmonary edema, the fluid buildup takes away from the alveoli surface area and disrupts the gas exchange of oxygen and carbon dioxide.

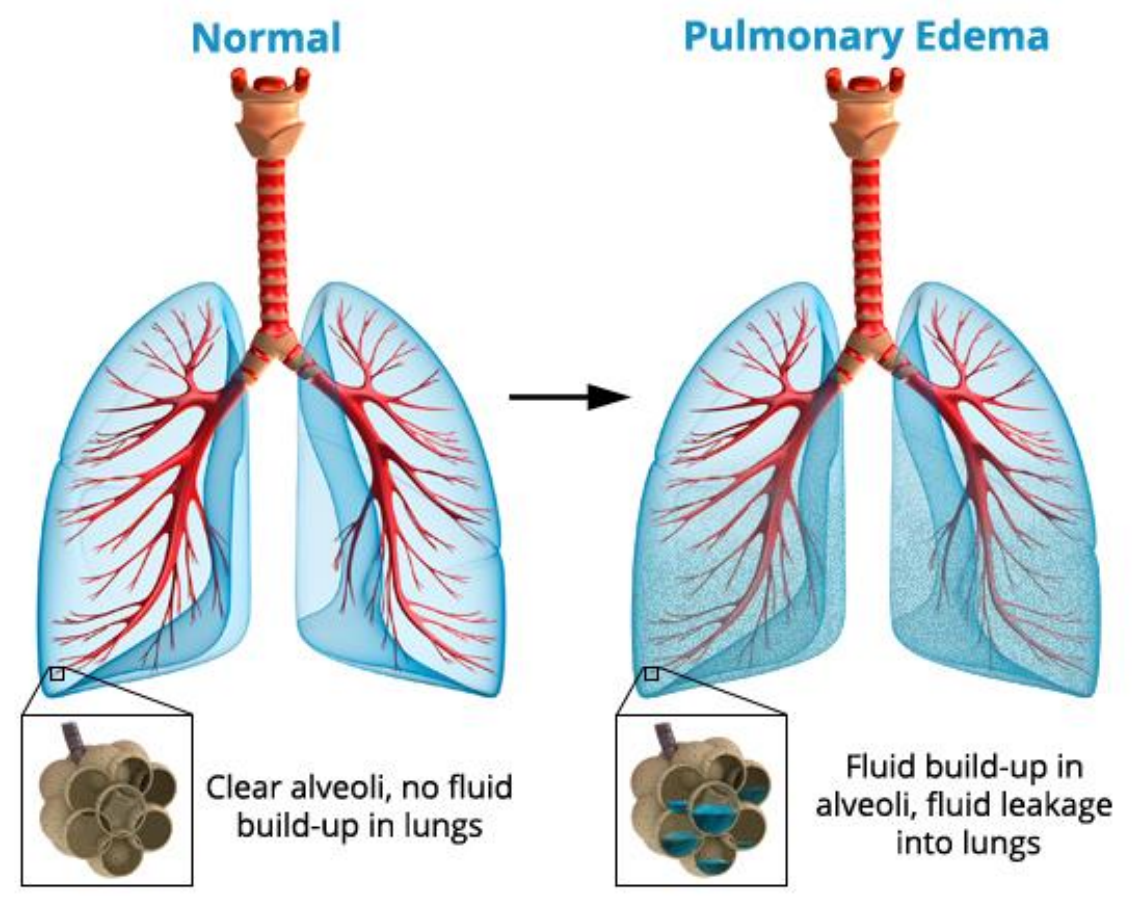

Figure 2: Fluid may build up in the alveoli or leak into the tissues around the bronchioles. [4]

This thesis will focus on heart-related cardiac pulmonary edema. Cardiac pulmonary edema arises when a diseased or overworked left ventricle is not able to pump out enough of the blood it receives from the lungs. As a result, pressure increases inside the left atrium and then in the veins and capillaries in the lungs. 
This results in another imbalance of Starling forces in the lungs and then causes fluid to be pushed through the capillary walls into the air sacs. When fluid builds up in the chest cavity, impedance decreases. This impedance decrease can be measured by pacemaker or ICD leads. Pulmonary edema is a serious condition and can cause death in as little as 60 minutes if left untreated. Figure 3 shows the progression of congestive heart failure and pulmonary edema as previously described.

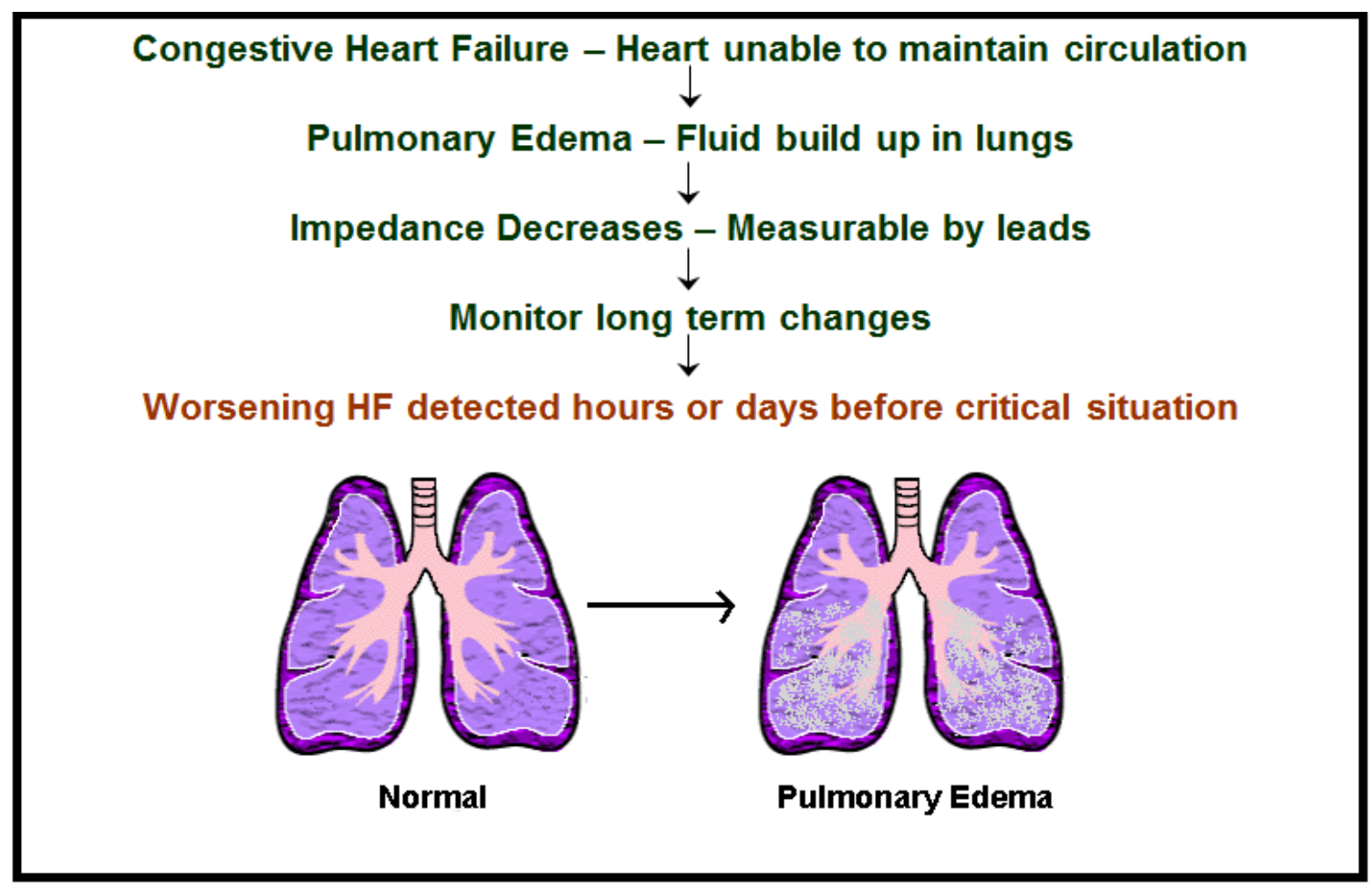

Figure 3: Pulmonary and Cardiac Edema progression. [5]

\section{Pacemakers and Implantable Cardioverter Defibrillators (ICDs)}

Pacemakers are small pacing pulse generators that are implanted under the skin, most often just under the collarbone. One or two lead wires will connect 
the heart muscle to the pulse generator. These pacemakers then use leads that are directly implanted into the heart to send electrical signals to start or regulate a heart rhythm. A pacemaker may be used to replace the functionality of a heart's natural pacemaker (the SA node) that is no longer functioning properly and has developed an abnormal heart rate or rhythm or in the case where the electrical pathways of the heart are blocked.

Implantable cardioverter defibrillators (ICDs) are very similar to pacemakers, but have an extra shocking capability. ICDs are capable of providing two levels of electrical energy to the heart: a low energy shock that can depolarize a heart causing it to beat, and a high energy shock that is delivered only if an arrhythmia is so severe that the heart is quivering instead of pumping or beating efficiently. In addition to all of the components that make up a pacemaker, the ICD system also contain a pulse generator and extra leads to deliver the high energy shock.

The most common method for implanting one of these medical devices is through the endocardial (transvenous) approach. In this method a local anesthetic is given to numb the implant area. An incision is made in the upper chest region where the leads and pacemaker are inserted. These leads are inserted through the incision made in the chest and the subclavian vein and are then guided to the appropriate chamber of the heart with the aid of a fluoroscopy machine. The lead tip is lodged in and attached to the heart muscle, while the other end of the lead that is attached to the pacemaker or ICD is coiled around and placed in a pocket created under the skin in the upper chest. 
Figure 4 shows both an ICD and pacemaker implant in a patient and how each is set up inside the patient. Figure A of Figure 4 shows an implantable cardioverter defibrillator implanted in the upper chest of the patient. Figure B of Figure 4 shows a pacemaker implanted in the upper chest. For each device, the wires with electrodes on the ends are inserted into the heart through the subclavian vein in the upper chest as previously described [6].

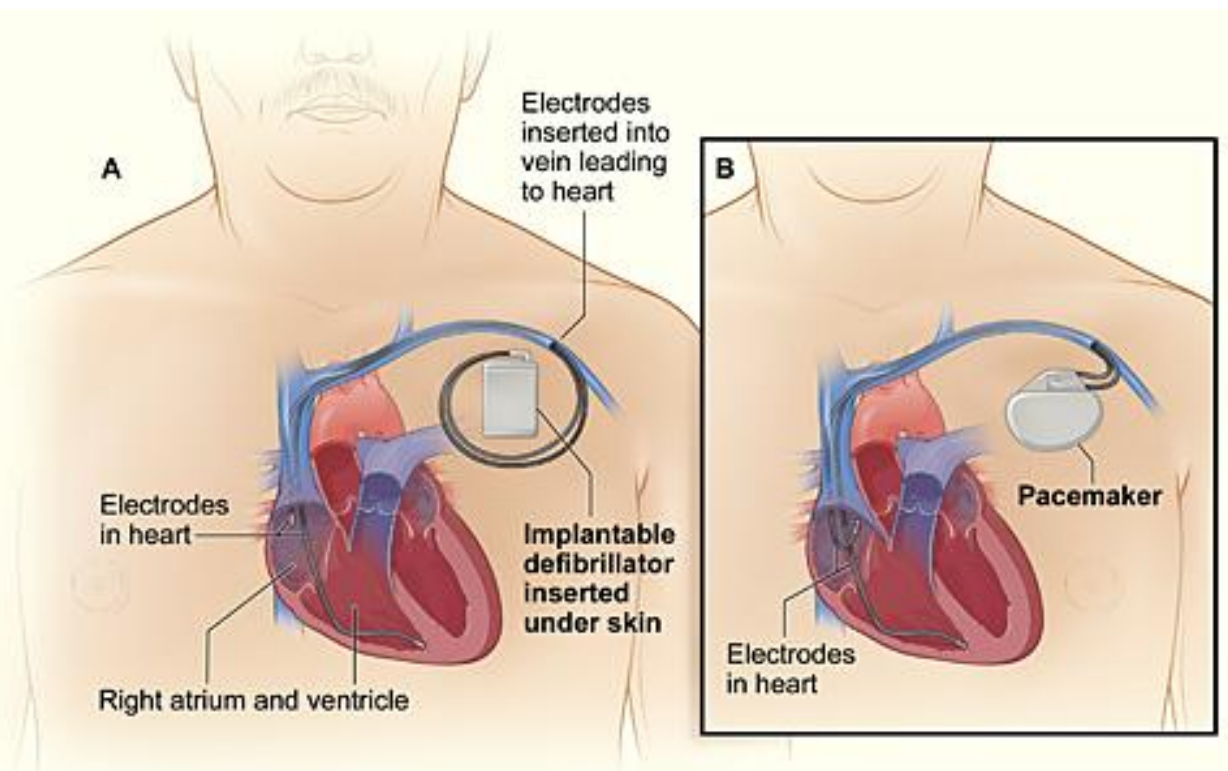

Figure 4: Placement of ICDs and pacemakers in the upper chest of patients [6].

With the use of up to six vectors, the pacemaker and ICDs can be used to take impedances across the intrathoracic cavity. The different lead configurations allow for these medical devices to measure impedances across different impedance vectors. By observing these impedances, these medical devices can detect when there is fluid buildup and thus be utilized to alert the 
patient of potential heart failure. Moreover, since many patients who are at risk of heart failure already have pacemakers or ICDs and the expanded capability of monitoring for pulmonary edema becomes a very useful feature to add on. These devices could be used to monitor impedance automatically and periodically. Figure 5 depicts a high level concept of the use of a pacemaker or ICD and their leads to take impedances in the thoracic cavity. This will aid in the monitoring of impedance drops due to fluid buildup in the chest region [7].

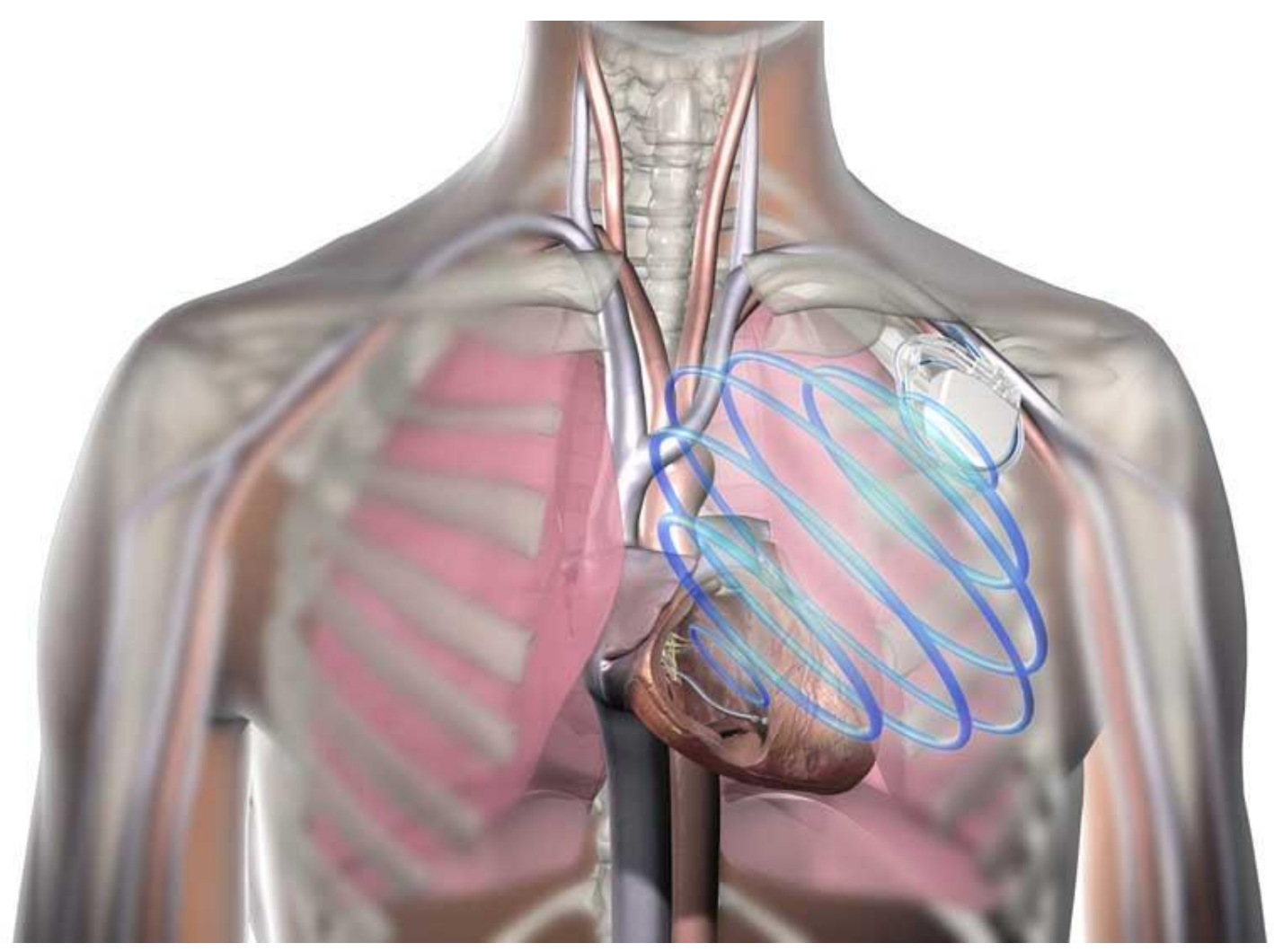

Figure 5: A high level depiction of a pacemaker or ICD taking an impedance measurement. [7]

A prospective study was performed with 34 patients with New York Heart Association class III or IV heart failure symptoms who were followed up for a 
length of two years for heart failure hospitalization [8]. During heart failure hospitalization, most patients underwent invasive right-sided heart catheterization that enabled correlation of acute hemodynamic and impedance changes. Once treatment of heart failure was initiated, impedance increased and correlated well with decreases in pulmonary capillary wedge pressure and net fluid loss. With a threshold value of $60 \Omega$-days, sensitivity to predict heart failure hospitalization was $76.9 \%$, with 1.5 false positive readings per patient-year. Early warning criteria were met $13.4 \pm 6.2$ days ( 5 to 22 days) before hospitalization [8]. In a larger prospective study, a similar pulmonary edema monitoring algorithm in pacemakers and ICDs was used in patients who underwent biventricular ICD implantation. The end point of that study was deterioration of heart failure on the basis of clinical assessment. Patients were notified by an audible alert when the fluid index threshold was crossed and were examined in an outpatient clinic for further evaluation. Data from 373 subjects were analyzed and showed that the algorithm had a $60 \%$ sensitivity (with $95 \%$ confidence interval $46 \%$ to $73 \%$ ) factor and a positive predictive value of $60 \%$ (with $95 \%$ confidence interval $46 \%$ to $73 \%)$ to predict heart failure events within at least 2 weeks [9].

Another prospective single-center study with 115 patients that had congestive heart failure showed that $67 \%$ of alerts were false-positives if the fluid index threshold level was left at nominal settings (60 $\Omega$-days). Analysis of the data suggested that perhaps a higher fluid index threshold level should be used (100 to $120 \Omega$-days) to enhance specificity and maintain reasonable sensitivity (60\% and $73 \%$, respectively) [10]. Thus, the limitations of this system remain its 
relatively low sensitivity and specificity. On the other hand, interpretation of false-positive alerts is not straightforward, because these alerts may identify subclinical heart failure exacerbation or other clinically important problems, including pneumonia or exacerbation of chronic obstructive pulmonary disease. The question of whether clinical outcome can be improved by early intervention based on changes in thoracic impedance is currently being investigated in large multicenter trials [11]. These studies also display that it is conceivable that impedance measurements from other leads or a combination of leads may yield improved results. There are promising experimental data to suggest that the addition of a left ventricular lead to the measurement vector could enhance specificity [12].

Figure 6 further depicts the results of this study and how a pulmonary edema monitoring algorithm is beneficial to patients. The graphs in Figure 6 depict thoracic impedance measurements in a heart failure patient utilizing Medtronic's OptiVol algorithm. The fluid status trend was obtained from a patient with severe heart failure and frequent heart failure exacerbations over a 12month period. The top graph shows a decrease of daily impedance value below reference summed and expressed as fluid index. The bottom graph shows variations of daily impedance measurements in the black line and reference impedance values in the gray line. When the patient was found to have worsened heart failure in the chronic heart failure clinic at point $A$, diuretic drugs were increased. He remained clinically stable until June 2009 at point B, when he was admitted to an outside hospital for fluid overload. He decompensated 
again at point $\mathrm{C}$, but responded to outpatient diuretic drugs. More recently at point $D$, he was found to have a 6-pound weight gain. Decline of transthoracic impedance was evident at the time of decompensation, with rebound after diuresis. In this patient, setting the fluid index threshold to 80 to $100 \Omega$-days would likely be specific and sensitive enough to warn against impending exacerbations of heart failure [8].

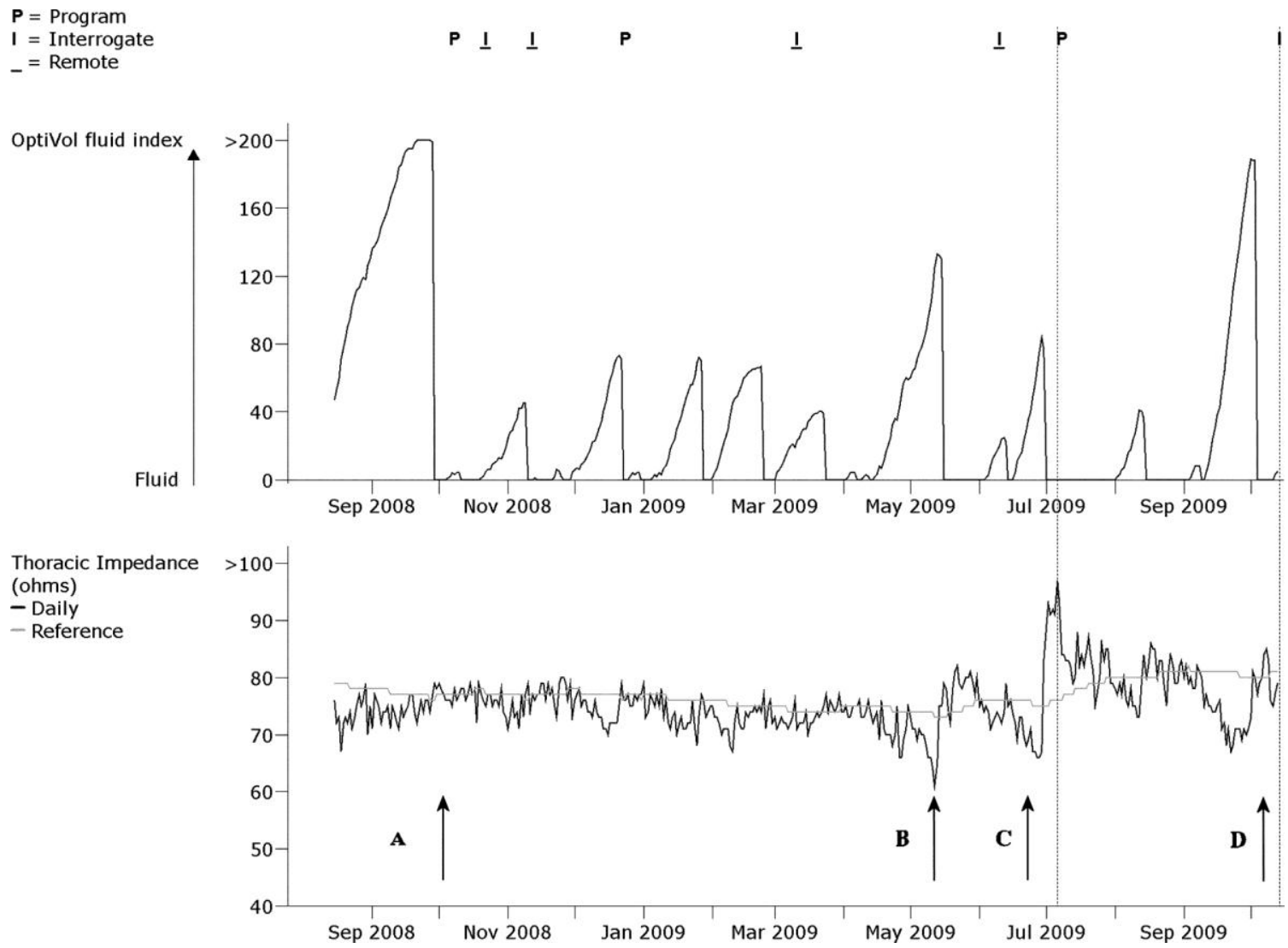

Figure 6: These graphs depict thoracic impedance measurements in a heart failure patient [8]. 


\section{Objectives}

\section{Project Objective}

The main objective of this thesis is to implement an algorithm for pacemakers and ICDs that will automatically and periodically monitor the thoracic cavity for drops in impedance indicating possible pulmonary edema. The implementation will be based on a wealth of research done by St. Jude Medical and other research papers and then outlined here. Constantly examining electrical impedance measurements across the lungs, these implanted medical devices can detect fluid in the lungs and early signs of cardiac failure. Long term monitoring of PE using impedance measurements can provide an early warning of fluid volume changes in the body. These changes can be detected hours or days prior to hospital admission so that medical intervention can occur before symptoms reach a critical level.

The theory is that as fluid builds up in the lungs the impedance drops. The pulmonary edema monitoring algorithm can be on or off and will utilize five to six vectors across pacing and shocking leads. Furthermore, the feature can be programmed to monitor the patient at several different programmable, periodic time intervals. This allows the physician to allocate more or fewer resources to monitor the status of fluid levels in the thoracic cavity.

The ultimate goal of the PE impedance algorithm is to be able to predict when a congestive heart failure is about to occur. A device based algorithm that 
could instruct the patient or physician to intervene early, before symptoms have developed, could avoid the need for hospitalization.

\section{Project Requirements}

The main objectives of this thesis are to describe a method of:

1. Automatically and periodically monitoring for decrease in impedance that might indicate an early onset of congestive heart failure.

2. Measuring impedance accurately across the thoracic cavity for fluid fluctuations. An average sensitivity of $50 \%$ or higher is desired.

3. Minimizing the amount of false positives in the algorithm. A false excursion rate (FER) of less than 1 false positive per year is desired.

4. Storing long and short term averages as a reference point to indicate whether impedance is decreasing.

5. Alerting the patient of potential congestive heart failure when the pacemaker or ICD determines a decline in impedance relative to long and short term averages.

\section{Project Theory}

Body fluids are good conductors of electricity. With this property, pacemakers and ICDs can use impedance checks to give an indication of how much fluid is built up in the thoracic cavity. Monitoring this thoracic impedance allows a pacemaker or ICD to determine if there is an increase in fluid in the lungs if there is a decrease in impedance. Monitoring will be accomplished by 
using up to six impedance vectors across pacemaker and ICD electrode points. A long term and short term average will be used as a reference for decreases in impedance. Through these checks, these implanted medical devices will be able to alert the patient to the danger of congestive heart failure in the near future. 


\section{Design and Implementation}

\section{Overview of Impedance Based Monitoring}

Impedance is constantly changing when measured across the chest between a pacing lead and pulse generator. The rapid changes in impedance are related to the cardiac and respiratory cycles as more or less blood or air fills the tissue between the monitoring electrodes. Less dynamic changes are seen when fluid accumulates in lung tissue. However, as pulmonary edema develops and builds up fluid, conductance improves causing a decline in impedance in the thoracic cavity. Therefore, the temporal changes and adequate filtering of the impedance signal not only allow the assessment of cardiac contractility or minute ventilation, but may also serve as a measure of changing fluid status.

This theory has been applied in clinical practice and impedance vectors are utilized in many pacemakers and ICDs. In one of the original studies using an ICD lead implanted in the RV apex, impedance was measured periodically between the RV ICD coil and left pectoral pulse generator with the minute ventilation sensor [8]. Constant current was applied between the electrodes with a measurement frequency of $16 \mathrm{~Hz}$. Measurements were averaged over a 2 minute period, and multiple samples were acquired during the day. A special algorithm was designed that plotted a slow-moving average of daily impedance values. Daily impedances were then compared against the moving average, and the difference was expressed as a fluid index. As pulmonary edema develops, daily impedance values decline and move away from the average values. Once 
the cumulative difference between the daily measurement and reference value reaches a programmable threshold, the detection criterion is met and a warning is delivered to the patient [13].

\section{Fluid Index}

The main aspects of the algorithm are contained in the moving average integral (MA), the negative trend, and short and long term averages. These portions of the algorithm are based on the assumption that the impedance decreases when the patient's heart condition worsens due to fluid accumulation in the body. All portions of this algorithm will be continuously running and has a number of programmable parameters, described in Table 1. 


\begin{tabular}{|c|c|c|}
\hline Parameter name & Explanation & Investigated values \\
\hline Long Average & The length of the long term average & $7,12,14,21$ and 28 days \\
\hline Short Average & The length of the short term average & $\begin{array}{l}16 \text { - } 64 \text { hours with a } 4 \\
\text { hours incremental step }\end{array}$ \\
\hline Hours Until Reset & $\begin{array}{l}\text { The number of continuous hours the short } \\
\text { average has to be above or equal to the } \\
\text { long average for the fluid index to be reset }\end{array}$ & $\begin{array}{l}4 \text { - } 52 \text { hours with a } 4 \text { hours } \\
\text { incremental step }\end{array}$ \\
\hline Vector & $\begin{array}{l}\text { Which impedance signal or signals should } \\
\text { be used when deriving the Fluid Index }\end{array}$ & $\begin{array}{l}63 \text { possible combinations } \\
\text { between all the electrodes. }\end{array}$ \\
\hline Threshold & $\begin{array}{l}\text { The Fluid Index threshold by which a } \\
\text { detection is made when the Fluid Index >= } \\
\text { threshold }\end{array}$ & $\begin{array}{l}\text { Depends on the Fluid } \\
\text { Index size. }\end{array}$ \\
\hline Time of day & $\begin{array}{l}\text { When, during the day, the impedance } \\
\text { values are measured. For example can be } \\
00-24,08-22 \text { (day time), } 22-08 \text { (night time). }\end{array}$ & $\begin{array}{l}\text { Entire day data, afternoon } \\
\text { data (12PM - 6PM), night } \\
\text { time data (12AM - 5AM) }\end{array}$ \\
\hline
\end{tabular}

Table 1: Parameter description used by all algorithms and what values were investigated.

The pulmonary edema monitoring algorithm works when it chooses one or more impedance signals and then calculating and resetting the Fluid Index based on those signals. This Fluid Index is compared against a programmable threshold. If the Fluid Index exceeds the threshold for more than 24 hours, then detection (excursion) is made. This is also illustrated in Figure 7. The first step of the algorithm is to measure the impedance vectors and then add together the combined impedance weights. From here the conductance and Fluid Index are calculated and then compared against the Fluid Index threshold. 


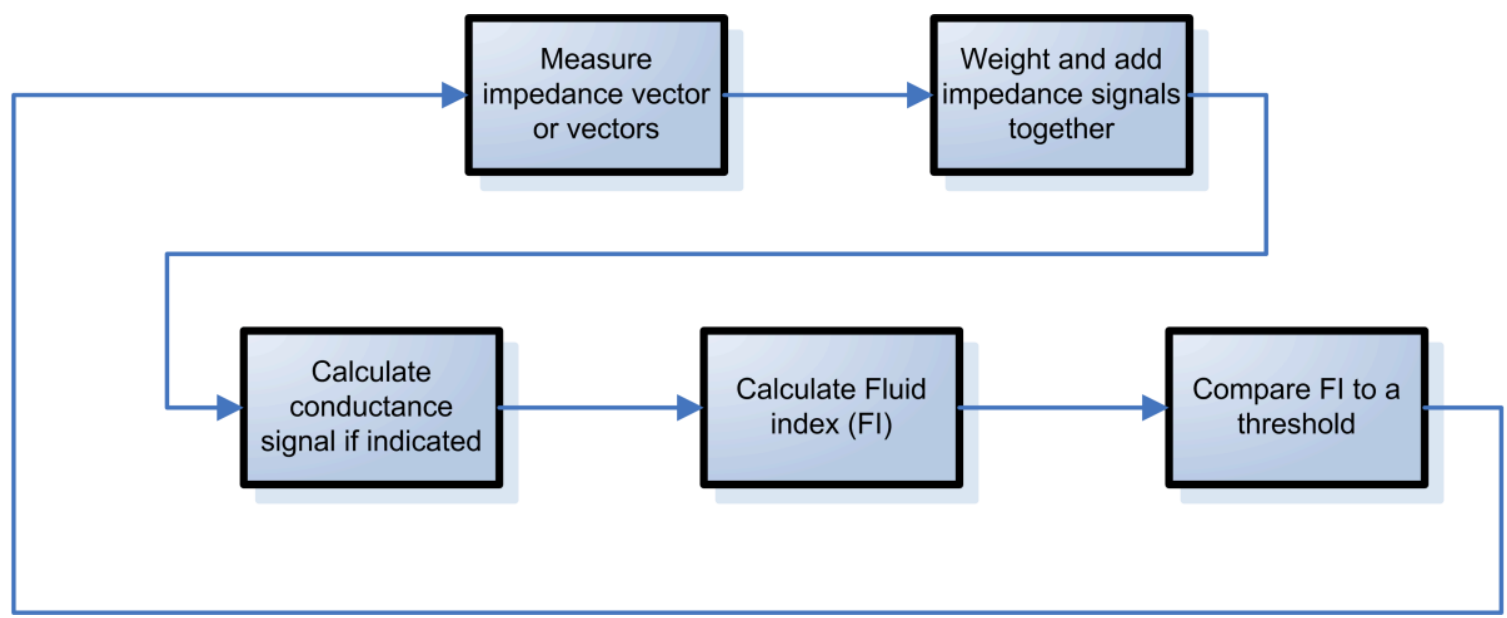

Figure 7: This shows a high level diagram for the fluid index algorithm. [14]

The calculation of the Fluid Index is shown in detail in Figure 8. The flow chart describes the method used to calculate the Fluid Index.

Fluid Index cannot be negative in value. Additionally, 


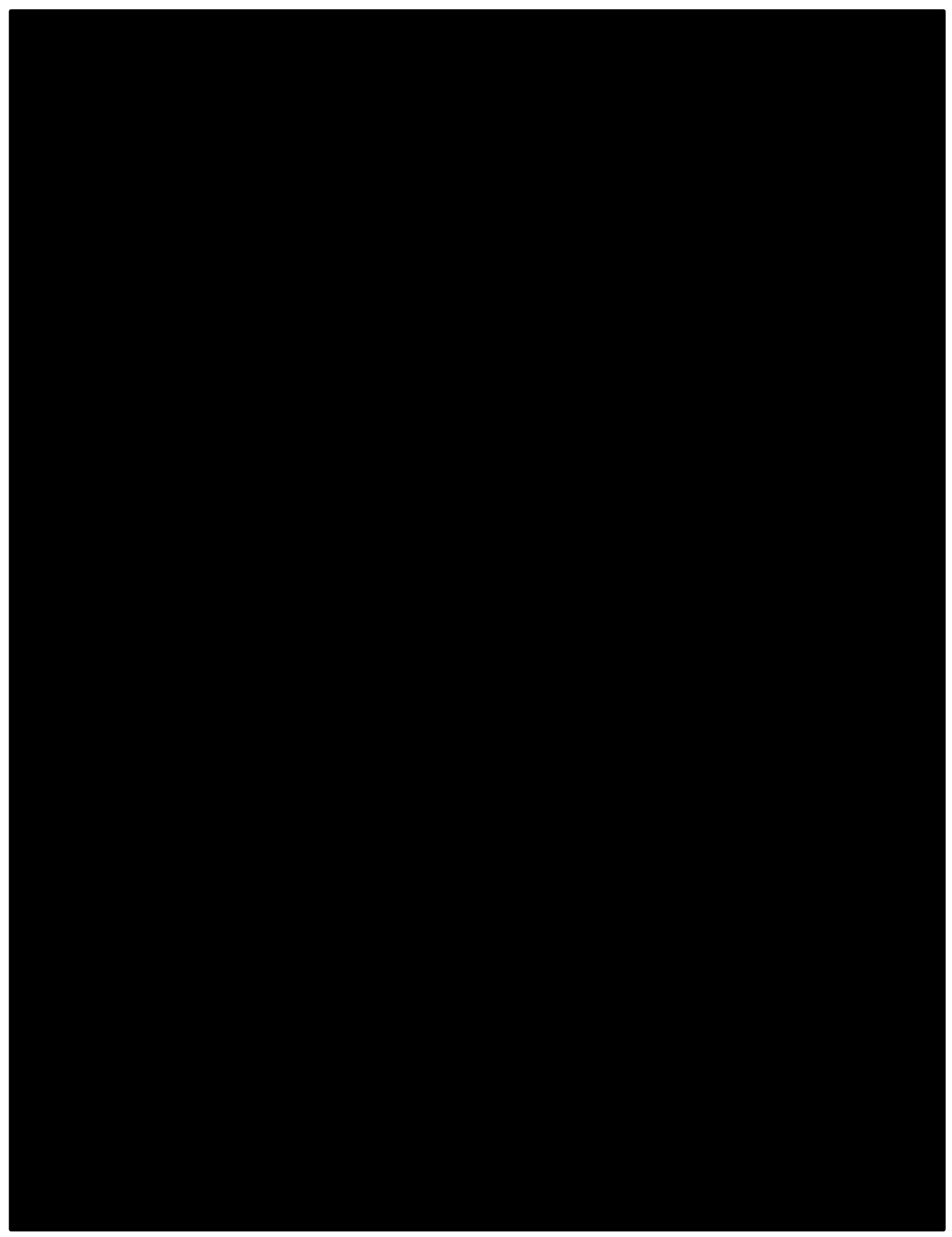

Figure 8: This is the flow chart that describes the method used to calculate the Fluid Index.

[Removed by SJM Legal] 


\section{Impedance vectors}

These values are shown in Table 2 [14].

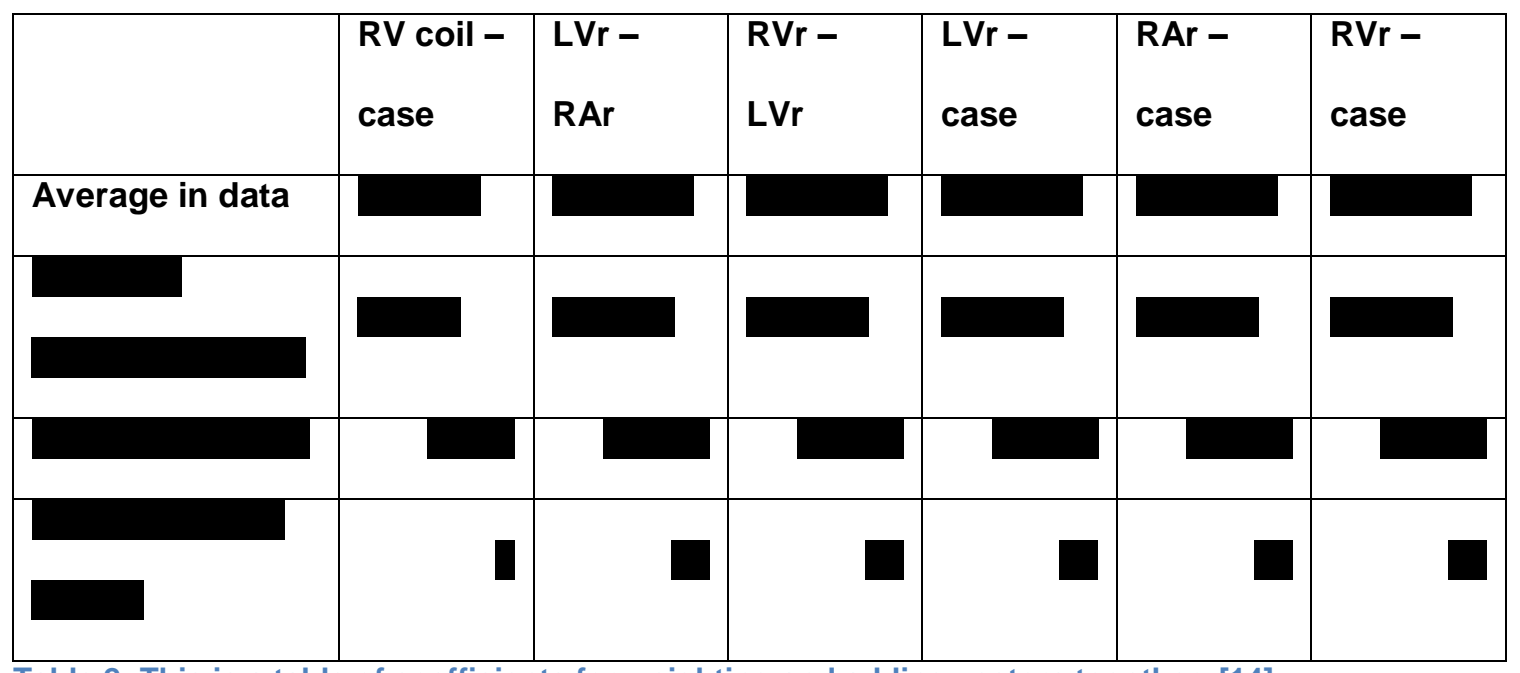

Table 2: This is a table of coefficients for weighting and adding vectors together. [14]

The formula used for adding vectors is:

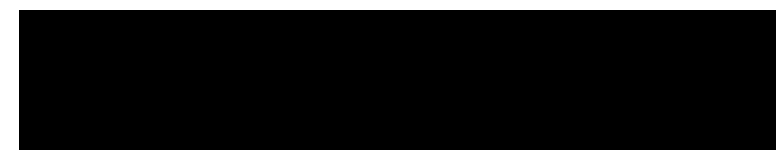



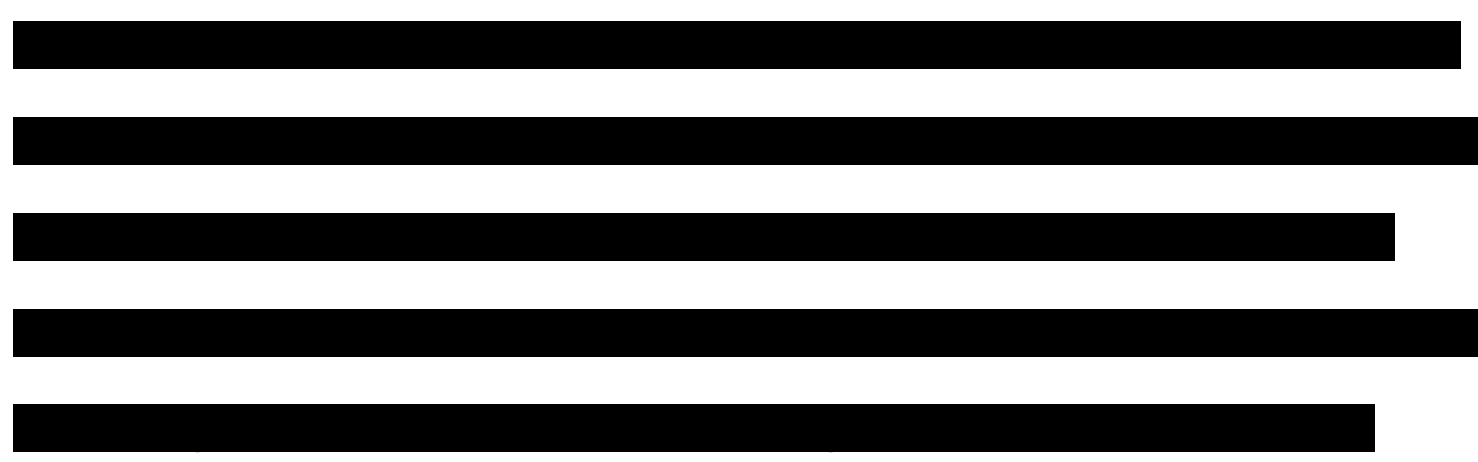

If only a single vector is to be used, no scaling would have to be accounted for. If a scaling factor is applied to the impedance signals as well as to the thresholds (apart from the Negative Trend algorithm), the algorithm output would be identical. Thus, it is possible to change the scale factors by replacing them by shift operations to avoid division and keep resolution if the same scaling is applied to the thresholds as well (apart from the Negative Trend algorithm) $[14]$

Since the Negative Trend algorithm only counts the number of days the impedance is dropping, neither a scale factor nor an offset applied to the signals will have an effect on the threshold. This simplifies the calculations even further. Consequently for the Negative Trend algorithm, the example above could be reduced to: 


\section{Moving Average Integral}
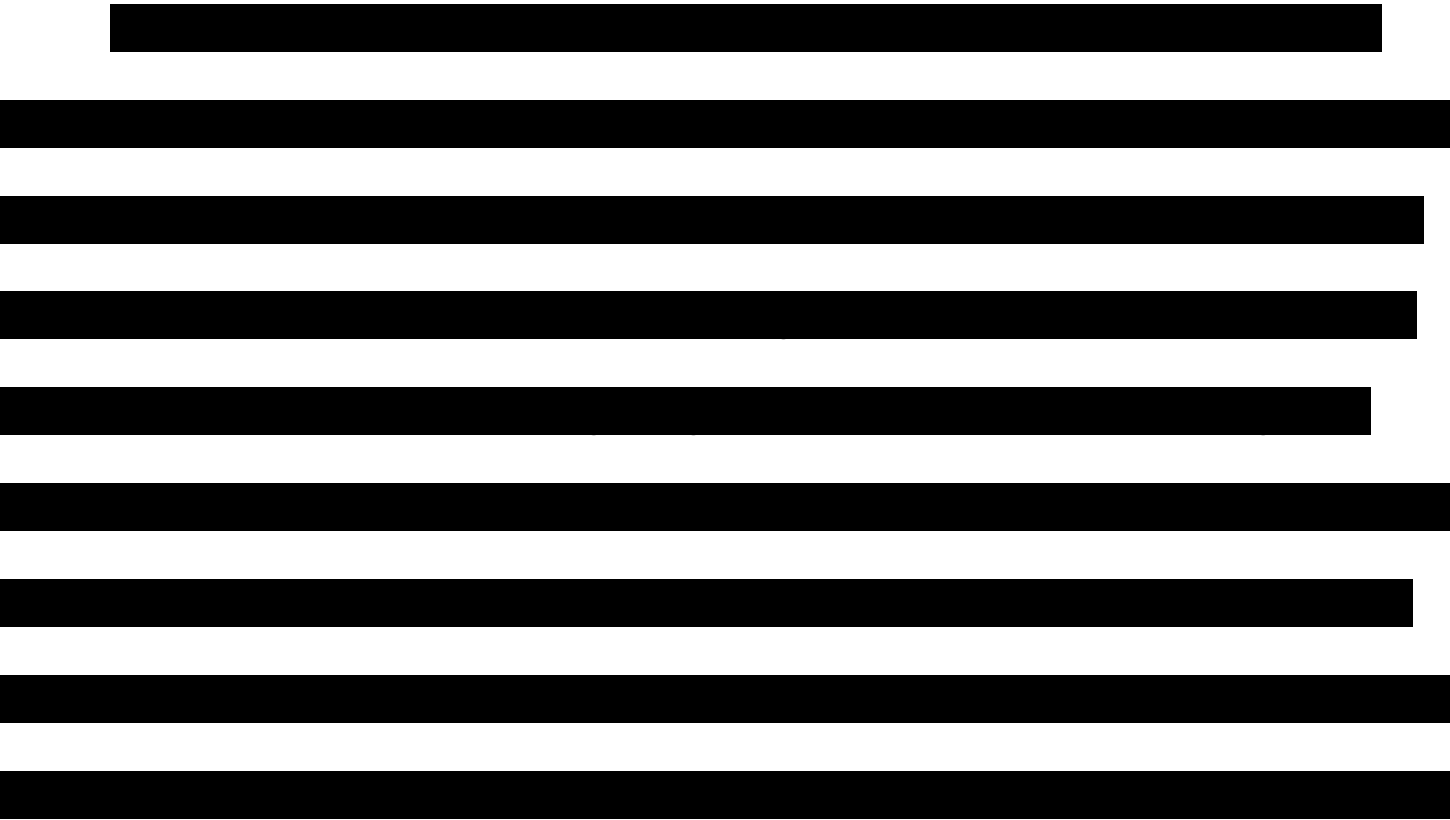

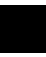

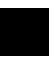

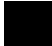

[14].

\section{Negative Trend}

The Negative Trend algorithm is a simple version of the above algorithms which simply counts the time the impedance has been dropping. The size of the drop is not important. If the short term impedance average is less than the long term average, the Fluid Index is increased. If the short term average is greater than or equal to the long term average for shorter periods of time (shorter than Hours Until Reset hours), the Fluid Index is decreased. However, the Fluid Index never can be below zero. If the short term average has been greater than or 
equal to the long term average for more than Hours Until Reset hours continuously, the index is reset to zero.

An example of how this algorithm works is shown in Figure 9. From top to bottom panels in Figure 9: normalized impedance (combined vectors), short average (blue), and long average (red); patient symptoms; Fluid Index (blue) with a threshold (dashed line); excursions (black) \& HF events (red). In this figure, the excursion is a TP. The very first heart failure event falls in the lead maturation period so that it is not detectable [14].
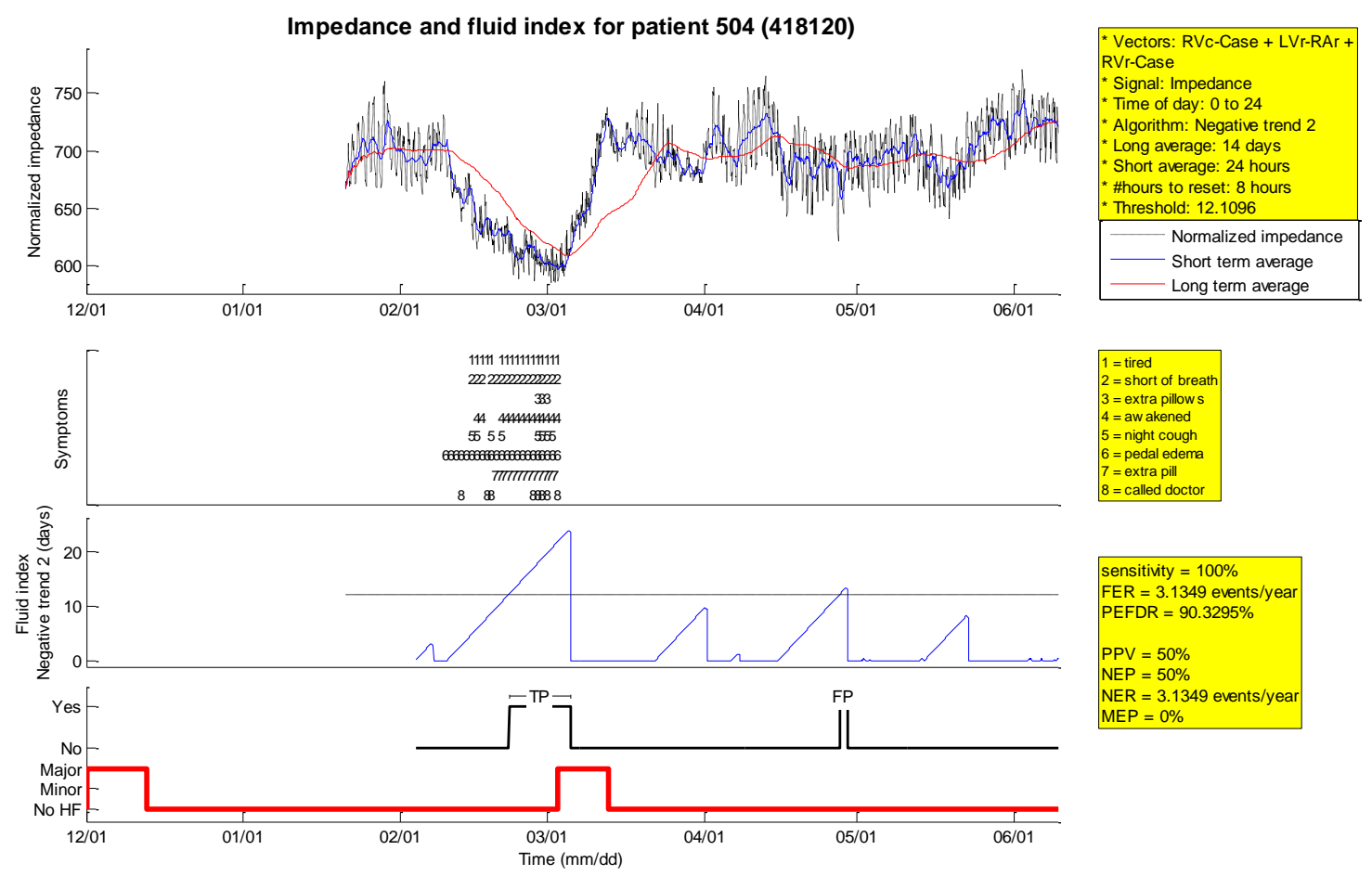

Figure 9: An example of Fluid Index (Negative Trend) for HF detection [14]. 


\section{Patient Specific Threshold}

The majority of analyses for the algorithm were completed with a fixed threshold for all patients. However, with patient specific threshold, further improvement could be achieved. Patient specific threshold was evaluated based on cost saving. For example, if a threshold other than the nominal for the particular patient could result in higher cost savings, the particular threshold value with optimized cost saving was determined as the specific threshold for that patient. Using equal steps (of 0.1 day) between 10 and 20 days (this range was tested and found to be adequate to cover reasonable changes in the threshold) for threshold, the optimal threshold for the majority of patients stayed at the nominal threshold while optimizing threshold for the remaining patients could achieve better sensitivity and/or false excursion rate (FER) as shown in figures 10 and 11. [14]

In figure 10, patient specific threshold histogram that gives optimal performance for cardiac resynchronization therapy defibrillator (or CRT-D) is shown. 53 out of 61 patients (87\%) have optimal performance at the nominal threshold, and $8(13 \%)$ benefit from changing the threshold. Sensitivity remains the same $(71.4 \%)$ and FER is improved from 0.56 to 0.14 with patient specific threshold. 


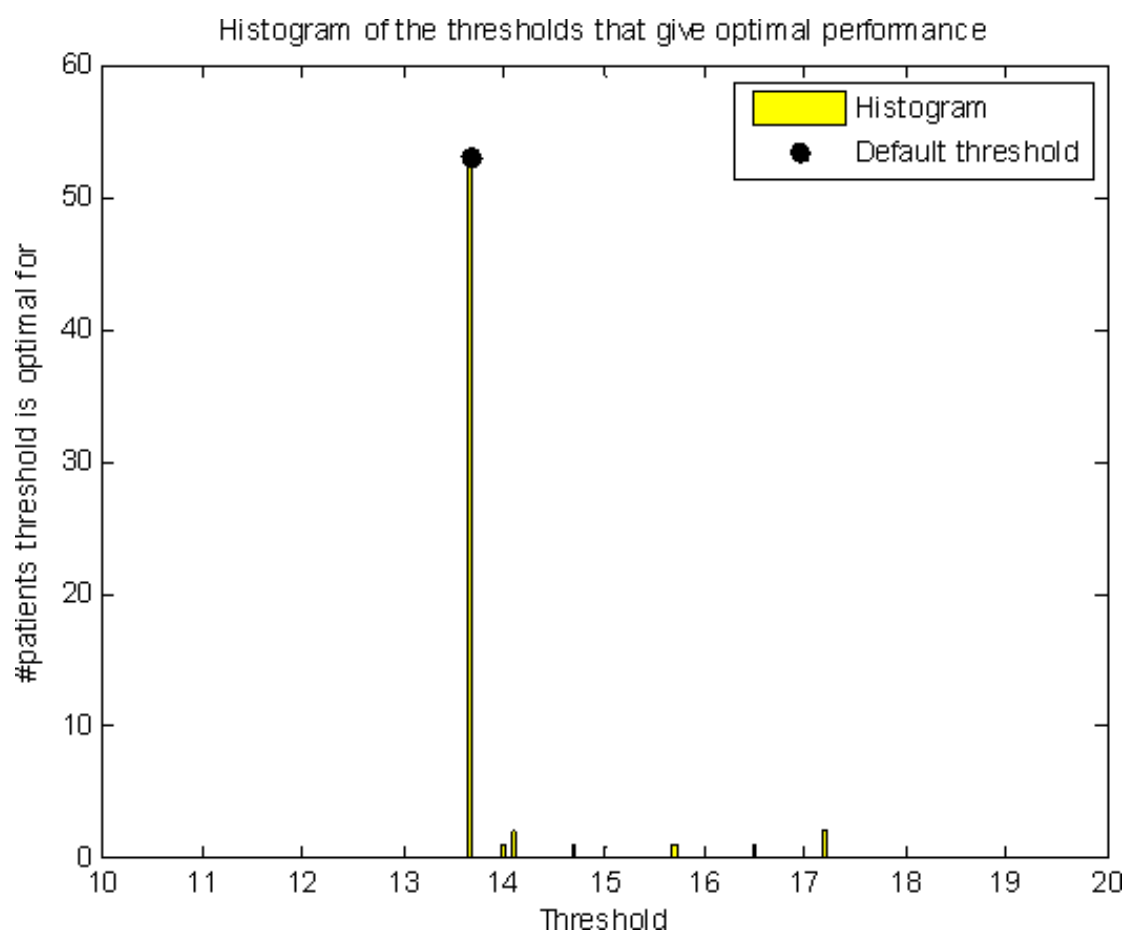

Figure 10: Patient specific threshold histogram that gives optimal performance for cardiac resynchronization therapy defibrillator (or CRT-D).

In Figure 11, patient specific threshold histogram that gives optimal performance for an ICD is shown. 48 out of 61 patients (79\%) have optimal performance at the nominal threshold, and $13(21 \%)$ benefit from changing the threshold. Sensitivity is improved from $61.9 \%$ to $76.2 \%$ and FER is improved from 0.63 to 0.21 with patient specific threshold. 


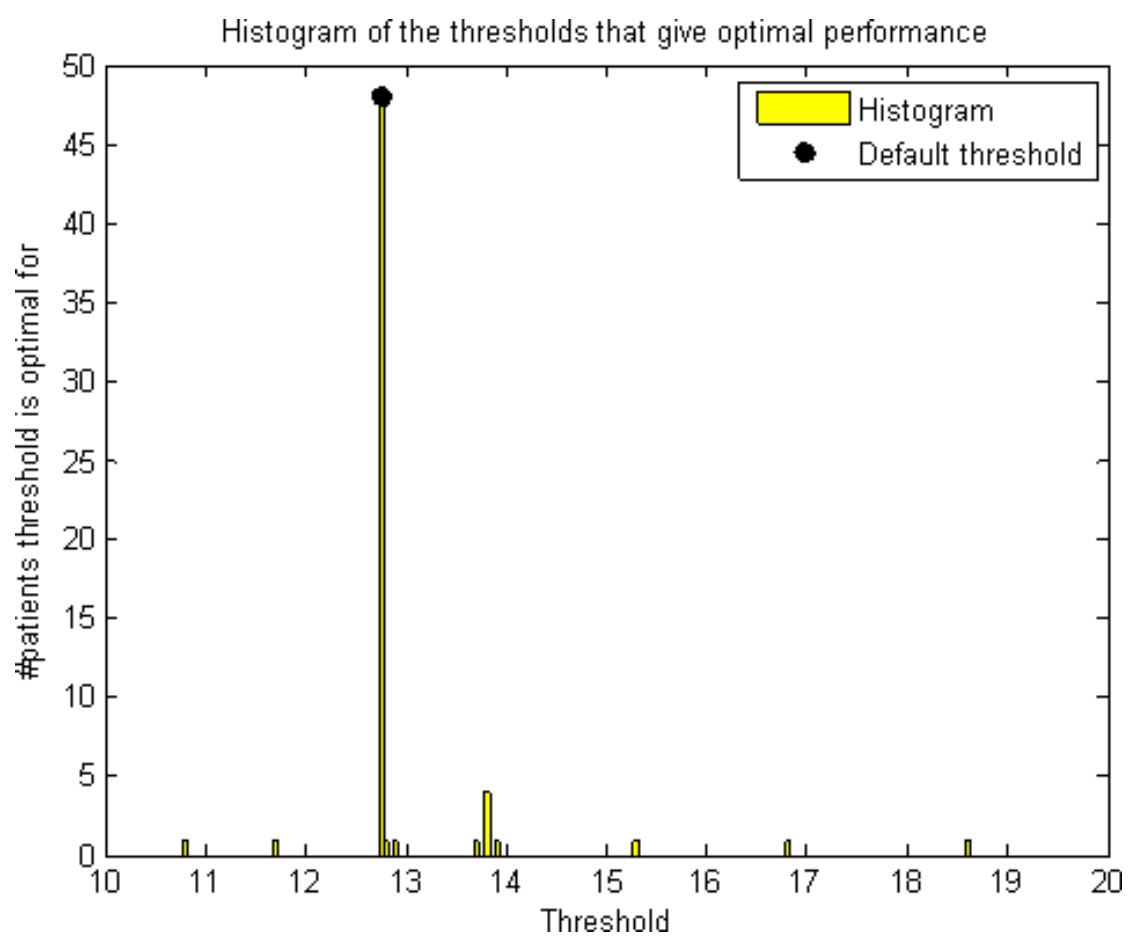

Figure 11: Patient specific threshold histogram that gives optimal performance for an ICD.

In reality, when one has programmable threshold values to accommodate specific patient needs, implementation would not be in fine steps of 0.1 day but rather coarse steps of 1 day (12 samples) except for the nominal and adjacent values, which would be rounded to the closest integer number of samples to achieve best performance in terms of cost saving. For example, a non-integer day of threshold may be chosen to better incorporate most patients to have specific threshold change needed in fine steps. With coarse steps, sensitivity and FER keep the same improvement as with fine steps except for FER for ICD, which is 0.24 instead of 0.21 . The actual threshold (displayed both in days and number of samples) and the displayed threshold to the user on the programmer (displayed in days) are shown in the tables below. In these tables only the 
nominal threshold and the two adjacent thresholds have different actual and displayed values.

\begin{tabular}{|c|c|}
\hline CRT-D & \\
\hline $\begin{array}{l}\text { Displayed threshold in } \\
\text { days }\end{array}$ & $\begin{array}{l}\text { Actual threshold in days (\# of } \\
\text { samples) }\end{array}$ \\
\hline 10 & $10(120)$ \\
\hline 11 & $11(132)$ \\
\hline 12 & $12(144)$ \\
\hline 13 & $13(156)$ \\
\hline 14 & $13.67(164)$ - nominal \\
\hline 15 & $14.7(176)$ \\
\hline 16 & $16(192)$ \\
\hline 17 & $17(204)$ \\
\hline 18 & $18(216)$ \\
\hline 19 & 19 (228) \\
\hline 20 & $20(240)$ \\
\hline
\end{tabular}

Table 3: This table shows the displayed and actual programmable thresholds in coarse steps for a CRT-D device. 


\begin{tabular}{|c|c|}
\hline ICD & \\
\hline $\begin{array}{l}\text { Displayed threshold in } \\
\text { days }\end{array}$ & $\begin{array}{l}\text { Actual threshold in days (\# of } \\
\text { samples) }\end{array}$ \\
\hline 10 & $10(120)$ \\
\hline 11 & $11(132)$ \\
\hline 12 & $11.7(141)$ \\
\hline 13 & 12.75 (153) - nominal \\
\hline 14 & $13.9(167)$ \\
\hline 15 & $15(180)$ \\
\hline 16 & 16 (192) \\
\hline 17 & $17(204)$ \\
\hline 18 & $18(216)$ \\
\hline 19 & $19(228)$ \\
\hline 20 & $20(240)$ \\
\hline
\end{tabular}

Table 4: This table shows the displayed and actual programmable thresholds in coarse steps for an ICD device.

\section{Patient Alert}

When the medical device confirms a decrease in the impedance in the intrathoracic cavity, the device shall trigger a clinical alert to be viewed by the doctor and a patient alert that will indicate to the patient that they need to see a 
doctor immediately. The patient alert will signal the patient via a 10 second vibrating notification from the medical device utilizing a vibrating motor. A second vibrating signal will occur 30 seconds after the first alert as a confirmation of the alert to the patient. After the initial pair of alerts, the device will continue to alert the patient once every hour until the patient notification alert is cleared by a physician. This alert will serve to constantly warn the patient of a life threatening condition that is imminent. 


\section{Results}

\section{Algorithm Optimization}

The results from a study performed by St. Jude Medical staff consisting of data on the combined pulmonary edema monitoring algorithms from June 2008 are shown below. Table 5 shows the settings that generate the best results according to the study discussed above for the different algorithm types [14]. In Table 5, the results show the optimal settings for the two different algorithm types and the performance of these in terms of sensitivity, false excursion rate (FER), and percent of event free duration spent in resolution (PEFDR). Both parts of the algorithms show a sensitivity value of higher than $50 \%$. When looking at FER, the negative trend algorithm falls below 1 false positive per year, while the moving average algorithm is higher than the allowed 1 false positive per year. This shows that the use of the moving average by itself is not sufficient to fulfill the project goals. However, the negative trend in conjunction with the moving average fulfills the project requirements set out in this thesis. However, the moving average algorithm may not be sufficient to meet the project requirements and cannot be used individually without the negative trend algorithm. 


\begin{tabular}{|c|c|c|c|c|c|c|c|c|c|}
\hline \multicolumn{7}{|c|}{ Algorithm settings } & \multicolumn{3}{|c|}{ Results } \\
\hline $\begin{array}{c}\text { Algorithm } \\
\text { name }\end{array}$ & Vector & $\begin{array}{c}\text { Lon } \\
\text { g } \\
\text { Ter } \\
\text { m } \\
\text { Avg }\end{array}$ & $\begin{array}{l}\text { Short } \\
\text { Term } \\
\text { Avg }\end{array}$ & $\begin{array}{l}\text { Hours } \\
\text { Until } \\
\text { Reset }\end{array}$ & $\begin{array}{l}\text { Time } \\
\text { of } \\
\text { day }\end{array}$ & $\begin{array}{c}\text { Threshol } \\
\text { d }\end{array}$ & $\begin{array}{c}\text { Sensitivit } \\
y\end{array}$ & $\begin{array}{c}\text { FER } \\
\text { (FP/year } \\
\text { ) }\end{array}$ & PEFDR \\
\hline $\begin{array}{l}\text { Negative } \\
\text { Trend }\end{array}$ & $\begin{array}{l}\text { RVc-Case } \\
+ \text { LVr-RAr } \\
+ \text { RVr-Case }\end{array}$ & $\begin{array}{c}14 \\
\text { days }\end{array}$ & $24 \mathrm{~h}$ & $8 \mathrm{~h}$ & $00-24$ & $\begin{array}{c}12.1096 \\
\text { days }\end{array}$ & $79 \%$ & 0.84 & $98 \%$ \\
\hline $\begin{array}{c}\text { MA } \\
\text { Integral }\end{array}$ & $\begin{array}{l}\text { LVr-RAr + } \\
\text { RVr-LVr + } \\
\text { LVr-Case + } \\
\text { RVr-Case }\end{array}$ & $\begin{array}{c}14 \\
\text { days }\end{array}$ & $24 \mathrm{~h}$ & $8 \mathrm{~h}$ & $00-24$ & $\begin{array}{l}100.8626 \\
\Omega^{*} \text { days }\end{array}$ & $93 \%$ & 3.75 & $92 \%$ \\
\hline
\end{tabular}

Table 5: This table shows the optimal settings for the two algorithms [14].

The results for the negative trend algorithm for single impedance vector used were also obtained and displayed in Table 6 . Table 6 displays the algorithm and algorithm settings matched with the appropriate the results associated with each configuration. Each vector shows a sensitivity of at least $71 \%$ or higher. However, the FER was far too high with vector yielding a result greater than 1. 


\begin{tabular}{|c|c|c|c|c|c|c|c|c|c|}
\hline \multicolumn{7}{|c|}{ Algorithm settings } & \multicolumn{3}{|c|}{ Results } \\
\hline $\begin{array}{c}\text { Algorithm } \\
\text { name }\end{array}$ & Vector & $\begin{array}{l}\text { Long } \\
\text { Term } \\
\text { Avg }\end{array}$ & $\begin{array}{l}\text { Short } \\
\text { Term } \\
\text { Avg }\end{array}$ & $\begin{array}{l}\text { Hours } \\
\text { Until } \\
\text { Reset }\end{array}$ & $\begin{array}{c}\text { Time } \\
\text { of } \\
\text { day }\end{array}$ & Threshold & Sensitivity & $\begin{array}{c}\text { FER } \\
\text { (FP/year) }\end{array}$ & PEFDR \\
\hline $\begin{array}{c}\text { Negative } \\
\text { Trend }\end{array}$ & $\begin{array}{l}\text { RVc- } \\
\text { Case }\end{array}$ & $\begin{array}{c}21 \\
\text { days }\end{array}$ & $48 \mathrm{~h}$ & $8 \mathrm{~h}$ & $00-24$ & $\begin{array}{c}12.3188 \\
\text { days }\end{array}$ & $71 \%$ & 1.3692 & $97 \%$ \\
\hline $\begin{array}{c}\text { Negative } \\
\text { Trend }\end{array}$ & $\begin{array}{l}\text { LVr- } \\
\text { RAr }\end{array}$ & 7 days & $24 \mathrm{~h}$ & $8 \mathrm{~h}$ & $00-24$ & $\begin{array}{c}5.5813 \\
\text { days }\end{array}$ & $93 \%$ & 4.81 & $94 \%$ \\
\hline $\begin{array}{c}\text { Negative } \\
\text { Trend }\end{array}$ & $\begin{array}{l}\text { RVr- } \\
L V r\end{array}$ & $\begin{array}{c}14 \\
\text { days }\end{array}$ & $24 \mathrm{~h}$ & $8 \mathrm{~h}$ & $00-24$ & $\begin{array}{c}9.7796 \\
\text { days }\end{array}$ & $79 \%$ & 2.46 & $95 \%$ \\
\hline $\begin{array}{c}\text { Negative } \\
\text { Trend }\end{array}$ & $\begin{array}{l}\text { LVr- } \\
\text { Case }\end{array}$ & $\begin{array}{c}14 \\
\text { days }\end{array}$ & $48 \mathrm{~h}$ & $48 \mathrm{~h}$ & $00-24$ & $\begin{array}{c}11.7908 \\
\text { days }\end{array}$ & $79 \%$ & 2.46 & $92 \%$ \\
\hline $\begin{array}{c}\text { Negative } \\
\text { Trend }\end{array}$ & $\begin{array}{l}\text { RAr- } \\
\text { Case }\end{array}$ & $\begin{array}{c}21 \\
\text { days }\end{array}$ & $48 \mathrm{~h}$ & $48 \mathrm{~h}$ & $00-24$ & $\begin{array}{c}5.5432 \\
\text { days }\end{array}$ & $100 \%$ & 9.05 & $71 \%$ \\
\hline $\begin{array}{c}\text { Negative } \\
\text { Trend }\end{array}$ & $\begin{array}{l}\text { RVr- } \\
\text { Case }\end{array}$ & $\begin{array}{c}21 \\
\text { days }\end{array}$ & $24 \mathrm{~h}$ & $8 \mathrm{~h}$ & $00-24$ & 9.875 days & $86 \%$ & 3.27 & $91 \%$ \\
\hline
\end{tabular}

Table 6: This table shows the optimal settings and performance for each of the six single vectors for the Negative Trend algorithm. [14]

Table 7 shows the performance of the algorithm for ICD and CRT-D devices when combining vectors together [14]. Patients with bad vectors and patients with non-cardiac events were also included in the study. The algorithm sensitivity decreases by approximately $10 \%$ when comparing to the performance from a single vector. However, the overall performance remains above $50 \%$ sensitivity and FER of less than $1 \mathrm{FP} / \mathrm{yr}$. A negligible difference of 0.04 false positives per year for FER and $0.1 \%$ for PEFDR is observed between the two devices. This shows that both types of devices are reliable when utilizing a 
combination of two vectors at a time to determine impedance decreases. These results support the results shown in Table 5 as well.

\begin{tabular}{|c|c|c|c|c|c|c|c|c|}
\hline \multicolumn{6}{|c|}{ Algorithm Settings } & \multicolumn{3}{|c|}{ Results } \\
\hline $\begin{array}{c}\text { Device } \\
\text { Type }\end{array}$ & Vector & $\begin{array}{c}\text { Long } \\
\text { Term } \\
\text { Avg (hr) }\end{array}$ & $\begin{array}{c}\text { Short } \\
\text { Term } \\
\text { Avg (hr) }\end{array}$ & $\begin{array}{l}\text { Hours } \\
\text { Until } \\
\text { Reset }\end{array}$ & $\begin{array}{l}\text { Thresh } \\
\text { old } \\
\text { (days) }\end{array}$ & $\begin{array}{c}\text { Sensitivit } \\
y\end{array}$ & $\begin{array}{c}\text { FER } \\
\text { (FP/yr) }\end{array}$ & $\begin{array}{l}\text { PEFD } \\
\text { R (\%) }\end{array}$ \\
\hline CRT-D & $\begin{array}{c}\text { RVC-Case } \\
+\mathrm{LVr}- \\
\text { Case }\end{array}$ & 288 & 48 & 20 & 13.67 & 71.4 & 0.56 & 98.6 \\
\hline ICD & $\begin{array}{c}\text { RVc-Case } \\
+\mathrm{RVr}- \\
\text { Case }\end{array}$ & 336 & 28 & 8 & 12.75 & 61.9 & 0.6 & 98.5 \\
\hline
\end{tabular}

Table 7: This table shows the optimal settings and performance for different device types for the Negative Trend algorithm. [14]

\section{Lead Type}

The study performed by St Jude Medical staff also detailed the lead types with the impedance range used. The results display which pacemaker or ICD lead would yield the best results for the use of this algorithm. St. Jude Medical QuickSite and QuickFlex leads were used in this study. Combining US and nonUS patient data, there are a total of 86 patients implanted with QuickSite LV lead, two of which have saturated and invalid LVr-Can impedance values. There are a total of 7 patients implanted with QuickFlex lead, two of which have high LVr-Can impedance values and a significant number of saturated samples. However, 
impedance of one of these patients recovered and became usable and valid. In Table 5, it shows that 5 out of the 7 QuickFlex leads showed impedance in the normal range as compared to QuickSite leads. [14]

\begin{tabular}{|c|c|c|c|}
\hline Point ID & Lead & $\begin{array}{c}\text { With saturated } \\
\text { samples? }\end{array}$ & $\begin{array}{c}\mathbf{Z}_{\text {LVr_an }} \text { at the end of } \\
\text { record }\end{array}$ \\
\hline 1603 & QuickSite & Yes & Saturated, $>750$ ohm \\
\hline 5303 & QuickSite & Yes & Saturated, $>750$ ohm \\
\hline 205 & QuickFlex & No,$~ 500$ ohm \\
\hline 301 & QuickFlex & No & OK, $\sim 475$ ohm \\
\hline 302 & QuickFlex & No & OK, $\sim 300$ ohm \\
\hline 402 & QuickFlex & No & OK, $\sim 400$ ohm \\
\hline 2601 & QuickFlex & Yes & OK, $\sim 600$ ohm \\
\hline 2602 & QuickFlex & No & OK, $\sim 525$ ohm \\
\hline 2705 & QuickFlex & Yes & Saturated, $>750$ ohm \\
\hline
\end{tabular}

Table 8: This table shows the lead types with the impedance range used for US and outside of the US patients. [14] 


\section{Discussion}

\section{Strengths}

There are several strengths to this approach of pulmonary edema monitoring. The first and foremost important benefit of a pacemaker and ICD based algorithm is that many patients at risk of heart failure already have these devices implanted. Since these medical devices are already implanted, it allows for expansion of use without the addition of other devices, surgery, or costly training. It is easy to see that a simple algorithm update can add to the additional usefulness of patient monitoring.

Additionally, pacemakers and ICDs have a five to ten year battery life [15]. This assures that pulmonary edema monitoring will be present during the time that these devices are implanted and operational. Since the algorithm is not always on, the monitoring system would cost little battery life as well.

\section{Weaknesses}

One of the weaknesses of this algorithm is that any complications arise from the implant and lead dislodgement would be difficult to troubleshoot. Once implanted, it is difficult to reach the device and leads again to readjust the system. Leads cannot be easily removed or repositioned without another costly surgery. If either of these conditions were to occur, the pulmonary edema monitoring system would not be able to provide accurate feedback. 
Furthermore, while the battery life is long at five to ten years as previously discussed, the negative aspect of this is that it would require another procedure to implant a replacement device when the battery is depleted. The surgery and additional device does add a significant cost to the patient every five to ten years. Since patients with this condition are usually frail, it is optimal to minimize operations and medical procedures performed on them. Any form of hardware update to this system would be cost inefficient or impossible without another device implant. Software updates are easier and would only require a trip to the doctor's office. 


\section{Conclusion and Future Work}

\section{Conclusion}

The implementation of the pulmonary edema monitoring algorithm is a large, successful step towards early detection of congestive heart failure. The results show that this algorithm was successful in reaching the project objectives by fulfilling the requirements set out in this thesis. The combination of the negative trend and moving average algorithms allow the pacemaker and ICD to automatically and periodically monitor for a decrease in impedance based on the

programmed parameters set. A sensitivity of $50 \%$ of higher was reached in all devices used. The number of false positives per year was limited to less than 1 per year. The use of long term and short term averages were used as a reference point for the moving average algorithm. Finally, the indication of any of these issues would trigger an alert to warn the patient of the potential life threatening condition.

This thesis shows that the objectives set out for pacemakers and ICDs has been accomplished. These pacemaker and ICD systems can be used to monitor the patient's fluid levels and therefore detect the onset of congestive heart failure. Utilizing impedance checks along with a short and long term slope comparison, these medical devices can check for fluid buildup accurately and constantly. Being able to check the patient's status constantly, periodically, and 
automatically, pacemakers and ICDs provide an added safety measure to their original intent of pacing and shocking the heart.

\section{Future Work}

This algorithm is promising technology to use in the constant monitoring and status of congestive heart failure. However, there are a few other technologies or algorithms that could enhance this technology.

One possible enhancement is the implementation of additional electrodes that would give the opportunity to sense from more locations for a more accurate reading. At times when leads become dislodged from the heart, additional electrodes would provide a potential backup extra vector to replace the one that was lost due to dislodgement. Additional vectors would also give the benefit of having a more precise way of measuring fluid in the chest cavity.

Another enhancement is expanding the algorithm to include cardiogenic impedances in reference to the thoracic impedance currently monitored. The addition of this trend with the thoracic impedance allows for a determination of whether the thoracic cavity of the patient generally has too much or too little fluid. This added algorithm change would give another measurement to improve the precision of detecting fluid buildup and congestive heart failure [16].

Furthermore, an additional improvement is the coupling of the pacemaker and ICD system to a drug therapy device. In response to a drop in thoracic impedance, diuretics such as furosemide or bumetanide can be administered to 
the patient to reduce this fluid buildup. These extra medical devices allow for immediate treatment during onset of a pulmonary edema. 


\title{
Acronyms and Definitions
}

\author{
ICD - Implantable Cardioverter Defibrillator \\ CRT-D - Cardiac Resynchronization Therapy Defibrillator \\ PE - Pulmonary Edema \\ CHF - Congestive Heart Failure \\ HF - Heart Failure \\ FI - Fluid Index \\ MA - Moving Average \\ FER - False Excursion Rate \\ PEFDR - Percent of Event Free Duration spent in Resolution \\ RV - Right Ventricle (Heart Chamber) \\ LV - Left Ventricle (Heart Chamber) \\ RA - Right Atrium (Heart Chamber) \\ LA - Left Atrium (Heart Chamber) \\ $\mathrm{RVr}$ - Right Ventricle ring (Electrode) \\ $\mathrm{LVr}$ - Left Ventricle ring (Electrode) \\ RAr - Right Atrium ring (Electrode) \\ LAr - Left Atrium ring (Electrode)
}




\section{References}

1. Centers for Disease Control and Prevention (2013, August). Heart Disease Facts. Retrieved September 20, 2013, from http://www.cdc.gov/heartdisease/facts.htm

2. Sebelius, K., Frieden, T. R., Sondik, E. J. (2011, February). Health, United States, 2010 With Special Feature on Death and Dying. Retrieved September 20, 2013, from http://www.cdc.gov/nchs/data/hus/hus10.pdf

3. Russo C. A., Andrews R. M. (2006, September). The National Hospital Bill: The Most Expensive Conditions, by Payer, 2004. HCUP, Statistical Brief No. 13. Retrieved September 30, 2013, from http://www.hcup-us.ahrq.gov/reports/statbriefs/sb13.pdf

4. heartfailure.org (n.d.). Retrieved October 1, 2013, from http://www.heartfailure.org/heart-failure/lungs/

5. kidney-support.org (n.d.). Retrieved October 1, 2013, from http://www.kidney-support.org/ckd-complications/1704.html

6. nhlbi.nih.gov (2011, November 09). Retrieved October 5, 2013, from http://www.nhlbi.nih.gov/health/health-topics/topics/icd/ 
7. optivol.medtronic.com (2010, September 27). Pulled October 5, 2013, from http://optivol.medtronic.com/what-is-optivol/index.htm

8. Yu C.M., Wang L., Chau E., Chan R.H., Kong S.L., Tang M.O., Christensen J., Stadler R.W., Lau C.P. (2005). Intrathoracic Impedance Monitoring in Patients with Heart Failure: Correlation with Fluid Status and Feasibility of Early Warning Preceding Hospitalization. American Heart Association, 112, 841-848. doi: 10.1161/CIRCULATIONAHA.104.492207

9. Vollmann D., Nagele H., Schauerte P., Wiegand U., Butter C., Zanotto G., Quesada A., Guthmann A., Hill M.R., Lamp B. (2007) Clinical Utility of Intrathoracic Impedance Monitoring to Alert Patients with an Implanted Device of Deteriorating Chronic Heart Failure. European Heart Journal. 28(15), 1835-1840. doi: 10.1093/eurheartj/ehl506

10. Ypenburg C., Bax J.J., van der Wall E.E., Schalij M.J., van Erven L. (2007). Intrathoracic Impedance Monitoring to Predict Decompensated Heart Failure. American Journal of Cardiology, 99(4), 554-557. doi: 10.1016/j.amjcard.2006.08.066 
11. Braunschweig F., Ford I., Conraads V., Cowie M.R., Jondeau G., Kautzner J., Lunati M, Munoz Aguilera R, Man Yu C, Marijianowski M, Borggrefe M, van Veldhuisen D.J. (2008). Can Monitoring of Intrathoracic Impedance Reduce Morbidity and Mortality in Patients with Chronic Heart Failure? Rationale and design of the Diagnostic Outcome Trial in Heart Failure (DOT-HF). European Jounal of Heart Failure. 10(9), 907-916. doi: 10.1016/j.ejheart.2008.06.016

12. Khoury D.S., Naware M., Siou J., Blomqvist A., Mathuria N.S., Wang J., Shih H.T., Nagueh S.F., Panescu D. (2009). Ambulatory monitoring of congestive heart failure by multiple bioelectric impedance vectors. American Journal of Cardiology, 53(12), 1075-1081. doi: 10.1016/jacc.2008.12.018

13. Kaszala, K., Ellenbogen, K.A. (2010). Device Sensing: Sensors and Algorithms for Pacemakers and Implantable Cardioverter Defibrillators. American Heart Association, 122, 1328-1340. doi:

10.1161/CIRCULATIONAHA.109.919704

14. Panescu, D., Bjorling, A., Nabutovsky, Y., Xi, C., Zhao, W., Qu, F., Wenzel, B., Naware, M. (2008). PE Impedance Algorithms Research Whitepaper.

15. mayoclinic.com. Pacemaker: Results. Retrieved, October 10, 2013, from http://www.mayoclinic.com/health/pacemaker/MY00276/DSECTION=results 
16. Bornzin, G.A., Koh, S., Park,E. (2008). System and method for monitoring thoracic fluid levels based on impedance using an implantable medical device. US Patent No 8032212 B2. U.S. Patent and Trademark Office. October 4, 2011 